released easily. The current was from $0 \cdot 0020$ to $0^{\circ} 0027$ ampere.

30 volts. The fingers, hands, wrists, the forearms and upper arms nearly paralysed; the fingers or hand could scarcely be moved; serious pains in the fingers, hands and arms, and the experiment not enclurable for more than ro seconds. The wires could, however, be released, but only by using the greatest determination. Current, 0.015 ampere.

40 volts. The fingers, hands and arms were instantaneously paralysed, and the pain was almost unbearable. The wires could hardly in any case be released. The pain could not be endured longer than 5 seconds.

50 volts. Again instantaneous paralysis of all the muscles of the fingers, hands and arms; the wires could not be released; the state endurable for 2 seconds at most, whence it was impossible to measure the current.

Having obtained the above results, the experimenter did not find it advisable to let the pressure exceed the 50 volts; the fact that when the hands were wet, it was impossible on 50 volts pressure to release the wires, seemed to prove to him that serious danger was just beginning at this point.

With dry hands he formed the following results :-

$$
\text { P.D. Effect. }
$$

40 volts. The fingers only tingle slightly; the current too feeble for ineasurement.

The effects gradually increasing and extending to the arms up to the shoulders, until at

80 volts. The fingers, hands and arms were almost cramped and aching in every part; great effort was required to release the wires; current from 0 '009 to 0.011 ampere.

90 volts. At the same moment in which the wire is seized, the hands are absolutely paralysed and the wire cannot be released again. The pains in the hands and arms were so violent that they caused the experimenter to call out involuntarily ; the effects could not be endured for more than I-2 seconds.

The experimenter now went back to 80 volts, and the difference was so great that the effects of this pressure seemed to be extremely feeble relatively to the effects at 90 volts pressure; this fact prevented him from trying the effects of pressure higher still

From these experiments Prof. Weber draws the following conclusions :-

"A simultaneous touching of both of the poles of an alternating current circuit is dangerous as soon as the pressure exceeds 100 volts ; and since it is impossible to set one's self free, the case must be regarded as fatal whenever immediate help is not at hand."

These results are consistent with several disasters which have happened in practical life.

In 1896 , in Horgen (Switzerland), a man, to prevent his falling down from a ladder, seized with both his hands two noninsulated leads with a P.D. of 240 volts between them, and was immediately killed.

In a mine in Silesia a workman seized in the same manner some non-insulated leads and was killed on account of his being unable to release them, the P.D. being 300 volts.

In the Electric Central Station in Olten a workman, desirous of proving to his companions that a pressure of 500 volts was quite safe, seized both of the leads and was killed instantly.

From this it is obvious that the general opinion of a pressure of 500 volts not being dangerous does not hold good, the limit being much lower. In spite of the great number of disasters which have already happened, the danger does not seem to have been generally appreciated, and workmen and erectors are often seen to deal with leads and apparatus of relatively high pressures in the most careless manner. That disasters have not taken place far more often may be due to the fact that in most cases help has been at hand instantly.

Entirely differing from these are the results of the other series of experiments $(\dot{b})$. In this case the person is supposed to stand at one of the poles itself, namely, the earth, from which

$$
\text { NO. } 1608 \text {, vOL. } 62]
$$

he is, however, rather well insulated by means of his shoes; and, as it will be evident from the results, the danger is in this case very small even at high pressures.

The arrangement used for this series of experiments consisted of twenty glow-lamps, each for 100 volts pressure, connected in series and all well insulated, the total alternating pressure between the first and the last lamp being 2000 volts. The free terminal of the first lamp was earthed, and between every two consecutive lamps a $6 \mathrm{~mm}$. copper wire was soldered to the main connecting the lamps. Between the earth and the first, second, third to the twentieth of the $6 \mathrm{~mm}$. wires, the pressure was consequently $100,200,300, \ldots 2000$ volts.

Standing on the ground, Prof. Weber touched the different wires-firstly, merely by a slight touch; secondly, by firmly gripping them in his hand. The experiments were made under two conditions, the experimenter standing firstly on moist gravel soil, and afterwards on clay covered by a thin layer of coal. dust.

Standing on moist gravel soil, he obtained the following results :-

P. D. Effect when the wire was Slightly touched. Firmly gripped.

800 volts. Feeble stinging of the No effect. skin.

Gradually increasing until at

2000 volts, Violent stinging of the Intense trembling of the skin. fingers.

Standing on clay covered with coal-dust, he obtained the following results :-
P. D.
Effect when the wire was Slightly touched.

200 volts. Scarcely sensible sting- No effect whatever. ing of the skin.

500 ", Gradually increasing. $\left\{\begin{array}{l}\text { The fingers begin to tingle } \\ \text { feebly. } \\ \text { Intense trembling of the } \\ \text { fingers, hands, arms and }\end{array}\right.$ ankle-joints.

rooo " Stinging like burning The effects in the fingers, by a flame. hands, arms and feet not endurable longer than I to 2 seconds; difficulty in releasing the wire.

I300 ,, Same effect.

The fingers, hands, and the arms are entirely paralysed, and the wire cannot be released.

From the last series of experiments it will be obvious that to touch one of the poles is not dangerous as long as the pressure does not exceed about rooo volts; the intense stinging which appears at the first slight touching serves as a protection against the danger, for the hand is instinctively drawn back rapidly.

The main result of these experiments is, then, that all pressures between 100 and 1000 volts must be regarded as equally dangerous, and consequently there is no reason for not using the higher pressures between 500 and 1000 volts, especially as they lead to greater economy in the working of the electric railway. Further, there is only a very little chance of the passengers or other persons coming into contact with both of the leads. 'To this danger the employés only are exposed, and being generally people with some electric training, they are acquainted with the danger and may be supposed to be sufficiently careful.

Finally, it is to be remarked that the authorities after these investigations allowed the use of a working pressure of $75^{\circ}$ volts as originally proposed.

\section{SEA COAST DESTRUCTION AND LITTORAL DRIFT.}

THE increasing number of seaside resorts that are constantly being established all round the coast of this country, and the necessity of protecting the sea front from the devastation of the waves, has led recently to greater interest being shown in the protection of the shores and cliffs.

The means taken to preserve our coasts are as diverse as many of them are ineffectual ; and in many cases are designed without any proper consideration being given to the way in which the waves act, or to the physical conditions which have to be dealt with in the management of the littoral drift; while 
frequently the amenities of the beaches of seaside resorts, and their use and enjoyment by visitors, are impaired by structures as ugly as they are useless to attain the object in view, and in other cases the construction of costly works is rapidly followed by their destruction by the sea.

It is proposed as shortly as possible in this article to state the conditions that have led to the present state of the cliffs and coast, and the conditions under which the material is drifted along the shore. For the purpose of illustration, the coast-line of the south-west of England between Start Point and the Solen has been selected, as this presents features of unusual interest for the study of coast destruction and the drift and accumulation of beach material. The cliffs between these two points consist of a series of rocks of varying degrees of hardness, showing in many places almost vertical faces to the sea, and ranging in height up to 500 or 600 feet. The destruction of these cliffs leads to the deposit, on the beach at their base, of fragments of rock, or inland gravels derived from their summits, which are converted by wave action into shingle, consisting of pebbles of varying character and size, but generally shaped into the form of flattened ovoids, readily distinguishing them from the angular gravels due to glacial drift, or the rounded pebbles rolled down inland rivers.

Originally, no doubt, these cliffs descended to the bed of the English Channel with the same slopes as characterise their land faces, and were washed by the deep water of the sea without the intervention of the sand beaches which now stretch from them, and which, where they exist, have an almost uniform inclination along all parts of the coast.

The present form of these cliffs is due to the destructive action of the waves, or to landslips and weathering from rain and frost. The wearing away has not been regular. Headlands composed of hard rocks project out boldiy to low-water mark and beyond, while the softer rocks which formerly ad joined them have been gradually worn away, leaving indents of various shapes and depths.

Some indication of the original position of the coast, and the distance to which it extended beyond the present line, is afforded by the remains of a raised beach, portions of which, consisting of pebbles which have been subjected to marine action, are to be found at Portland Bill on the east of Lyme Bay, at Hopes Nose, near Torquay, at Brixham and in Start Bay on the west.

These beaches are at a much higher level than the present water-line. The direction of this old beach was located by the late Sir J. Prestwich as running in an unbroken line at ten miles outside the present shore between the thirteen- and twentyfathom contour. There are also patches of gravel near the nine-fathom contour extending all round the bay at about a mile from the shore.

The coast-line has been broken up into three principal indents between the two headlands, namely, Lyme Bay, Weymouth Bay and Bournemouth Bay; the contour of which again is split up into numerous minor bays and coves, the greater number of which have their own peculiar characteristics and contain their own peculiar accumulations of shingle. Two of these shingle banks, namely, the Chesil Bank in Lyme Bay, and that at Hurstcastle at the entrance to the Solent, are, perhaps, the most remarkable accumulations to be found anywhere round the coast of Great Britain ; while at Axmouth is one of the most extensive landsilps of which there is any record. The fight between sea and land is continuous and unceasing, with the result that the area of this country is gradually being reduced.

The rivers which discharge into the sea along the south coast are few and insignificant in character, and are utterly in. capable of transporting from the land the large amount of stones or sand now found on the coast. In some cases they have been blocked up by the littoral drift. A careful consideration of all the circumstances can therefore only lead to the conclusion that some of the results which have been attained must be due to other and mightier forces than those now in existence. These forces may probably be ascribed to the same agencies that gave to this country the shape which it now assumes, and by which the valleys and rivers were scooped out.

At the close of the last great Ice Age the melting of the vast bed of snow which then covered this country must have led to large torrents of water escaping seaward, which would carry with them the debris from the rocks broken up by frost and ice, in the shape of boulders, gravel and sand; and besides leaving deposits in the valleys and those which are to be found on the summit of the cliffs, would carry the degraded material to the sea and form a talus at the level of the water. This deposit, after the wear and tear caused by the waves during long ages, resulted in the present sand beaches.

It is certain that the enormous mass of sand which now covers the littoral of the sea cannot have been deposited by existing agencies. The degradation of the cliffs that takes place is quite inadequate to account for its existence ; more especially as only the harder rocks have afforded the material of which the sand is composed, the softer detritus having been carried away in suspension to the depths of the ocean. The sand of the seashore consists almost entirely of grains of quartz of a nearly uniform size, and even where flints abound in the sea cliffs and in the shingle on the beach, this material is conspicuous by its absence in the sand of the shore.

As pointed out in my letter in NATURE of November 30 last, only about one-third of the flints lying on the beaches along the south coast, not only in the part dealt with but also on those bordering on the chalk cliffs extending from Brighton to the North Foreland, and in the large accumulations at the Chesil Bank and Dungeness, are derived from the chalk, the colour of the majority of the flints being different shades of brown, grey, white and red, the former being most prevalent, whereas flints from the chalk are invariably black with a white exterior coating. If the above assumption as to the deposit of land detritus on the coast be correct, it affords a reasonable explanation of this phenomenon.

Another prouf that the large accumulations of shingle along the coast are not due to agencies at present operating, is afforded by the fact that the Chesil Bank and Hurst Bank, where the supply of new material drifting along the coast is limited, have not varied materially in shape or increased in size during the time to which the most ancient records relating to them extend, the fresh supply coming from the cliffs being only sufficient in these cases to make up the wear and tear caused by the waves.

The supply afforded by the degradation of the cliffs is after all limited in quantity, and only about equal to making gond the waste due to the constant wave action on the shingle. If from any cause an abnormal accumulation takes place on any particular part of the coast, denudation immediately sets in on the coast beyond. Instances of this are afforded by the extension of the Point at Dungeness and the banking up of the shingle on the west side, which has led to a diminished supply all along the Dymchurch and Hythe coasts. The construction of the Admiralty Pier at Dover has led to the denudation of the coast to the northward along St. Margaret's Bay. The pier at Shoreham Harbour for a time denuded the supply at Hove and Brighton; and it is found universally to be the case that where the drift has been stopped by the debris from the fall of the cliffs acting as a groyne extending out to low water, or where artificial works have arrested the progress of the drift, the coast beyond has suffered from denudation.

There is no continuous drift of shingle throughout the whole length of this coast, but the material is confined to the various bays and the banks where it has been accumulated. It has been stated that the land gravel found along the foot of the chalk cliffs at the east end of the English Channel may have been derived from the waste of the gravel beds of the cliffs of Dorset and Hampshire, and that pebbles found on the Chesil Bank have been derived from the coast of Devon; but an examination of the coast shows that under present conditions, at any rate, this is neither the case nor physically possible. For this to have occurred the shingle must not only have passed the numerous headlands which project into the water, but also the approaches to Southampton and Portsmouth, in which the depth of the channels is from five to ten fathoms.

Nearly every bay and cove along the coast here dealt with has its own peculiar accumulation of shingle, which does not travel beyond the projecting headland, and in many cases there are long intervals along the shore where the rock is bare. Thus the shingle in Slapton Bay is of a different character from that found in any other part of the same coast. It consists almost entirely of round white quartz pebbles, resembling peas in shape, and averaging from an eighth to a quarter of an inch in diameter. This shingle not only covers the beach, but has been thrown up into a bank, the top of which is above the level of high tides, and has drifted across a deep indent in the bay, into which two fresh-water streams discharge, entirely closing this from the sea and forming it into a fresh-water lake about two miles long. The quartz pebbles of the Slapton beach do not drift beyond the eastern horn of the bay, and are not to be found in the next recess. All along the Devonshire coast

NO. I 608, vOL. 62] 
the numerous bays and coves have beaches on which are accumulated shingle derived from the limestone, slate, greenstone, and other rocks which surmount them, while in others there is an absence of shingle and only sand is found. In the bay lying between the headland of the Exe and that at Otterton Point, the beach at Budleigh Salterton is strewn with quartzite boulders and pebbles derived from a large bed contained in the cliffs bordering this part of the bay. These pebbles are of a pink colour, some having marks on them like blood spots. No stones of a similar character are found in the next bay, the drift being stopped by some rock ledges which project out from Otterton Point and form a natural groyne. The shingle in front of Seaton consists almost entirely of the chert and fint derived from the rocks at Beer Head. Beyond this, for several miles there is no continuous bank of shingle, but accumulations are to be found in the bight of the bays, the pebbles being derived almost entirely from the gravel beds in the cliffs. The shingle on the east side of Bridport Harbour is of a different character from that on the west shore, and resembles in size and shape that at Slapton, but the colour of the pebbles is different, these consisting of flint instead of quartz. This small shingle continues all along the coast, and up to the commencement of the Chesil Bank.

The drift of shingle along the shore only takes place above the line of low water, and within the zone covered by the horizontal range of the tide, and it does not accumulate below the line of mean tide level, except where its progress is stopped by encountering an obstruction, and when the quantity has become so great as to extend out into deep water. When the shingle encounters a river of any magnitude, it extends out in a spit across the entrance to the estuary, causing the tides to be diverted from their direct course, and to flow round the end ; or else the channel becomes diverted from its course to the leeward, and made to flow in a course parallel with the coast for some considerable distance. Examples of this are found along the coast here dealt with, in the Spits across the estuaries of the Teign and the Exe, and that across Christc urch Harbour, and in the diversion of the streams at Seaton and C?armouth.

The Chesil Bank, which commences near Abbotsbury and extends in a scuth-easterly direction to the island of Portland, a distance of $10 \frac{3}{4}$ miles, has in its course diverted several small streams, which now flow in a channel running parallel with the bank. The width of this great mound of shingle is about 500 feet, and its height varies from 32 to 53 feet, its top being from. 23 to 43 feet above high tides.

Hurst Castle shingle bank extends out from the mainland at the entrance to the Solent for $\mathrm{I} \frac{1}{2}$ miles, terminating in a hooklike formation on which stands Hurst Castle, erected in the reign of Henry VIII. The bank slopes down across the Solent for a distance of three miles, leaving only a deep narrow passage between its foot and the Needles, in which is from 4 to 9 fathoms of water. This shingle bank forms on its southern side a steep submarine cliff from 20 to 70 feet in height, the face being very steep and dropping almost suddenly from a dry bank to several fathoms of water. So far as any record exists, this bank has not increased or diminished in size or undergone any material alteration since the castle was built. Eastward of the bank there is no drift of shingle, the foreshore for several miles consisting of a wide belt of alluvial deposit.

Another lesson this stretch of coast appears to teach is, that the theory which has generally received acceptance, that the prevailing direction in which the shingle is drifted along any given coast is always in the same direction as that of the prevailing wind, is not founded on fact. This theory may be said to have been settled on the facts brought forward in a paper read at the Institution of Civil Engineers in 1853 on the Chesil Bink, and the discussion which followed.

A careful examination of the facts mentioned in that article do not appear to warrant any such conclusion, but, on the contrary, tends to disprove it. The local movement of shingle along the south-west coast, and also along the other parts of the seashore, are certainly not uniformly in accord with the direction of the prevailing winds of this country. Approximately, the wind in England blows for two-thirds of the year from the south-west. On the east coast the general direction of the drift is from north to south. On the south-west coast the general direction is from west to east. From Beachy Head to Dover it is north-east; from Dover to the North Foreland, northerly; from the North Foreland to the mouth of the Thames, westerly; and north of the Thames south-westerly.
On the west coast, the drift is from south to north, up to the middle of the Irish Channel : and north of this, from south to north; and up the Bristol Channel from west to east. In all these instances the movement is in the same direction as the set of the flood-tide.

Although this is the general direction of the drift, there are numerous instances where, owing to the varying set of the tides, the drift moves in three or four different directions within very short ranges. Taking the example of Lyme Bay and the Chesil Bank, the locality where the prevailing wind theory was established, the facts as given by the author of the paper were: That the prevailing direction of the wind on this part of the coast varied between S.S.W. and S.W. $\frac{1}{2}$ W., which is practically at right angles to the Chesil Bank. If then the drift is in the direction of the prevailing wind, this should lead to a north-easterly movement. The bulk of the materials of which the bank is composed are stated in the paper to have come from the cliffs to the west of the bank, and therefore must have travelled in a south-easterly direction. At the east end of the bank the shingle derived from the debris of Portland moves in a northerly direction. On the other side of the island of Portland, in Weymouth Bay, the shingle is moved in a southwesterly direction; therefore, within the space of five or six miles, the drift is in three opposite directions, not one of which is in the direction of the prevailing winds, but all of which are in the direction at which the flood-tide strikes the shore. Further, it is correctly stated that the effect of winds from the south-west tends to pull down the bank, which is restored again to its normal condition during calms and north-east winds.

Along all tidal coasts it will be found that the general direction of the drift is the same as that of the flood-tide, and that the beach material in bays is moved in the same direction as that in which the wavelets due to the flowing tide break on the beach. It is not contended that shingle is not drifted by waves due to wind. On the contrary, it is a well-known fact that shingle is frequently drifted, first in one direction and then in the opposite, during the occurrence of gales blowing from different quarters obliquely on the shore, and that the beaches are alternately heaped up with material at one place and denuded at another. This process, however, is only occasional and intermittent, and beyond it there is a regular and continuous drift in one given direction, the main course along the coast being in the same direction as the flood-tide, the building up of shingle banks being most active during calms and off-shore winds.

After a long and careful investigation the writer has satisfied himself that the building up of shingle banks and the regular and continuous drift that takes place along the coast are due to wave action caused by the flow and ebb of the tides. As the great tidal wave moves along the deep water of the channels surrounding the coast, its crest is in advance of the sides, which encounter the friction of the shallower water. The swelling tide therefore meets the shore at an angle oblique to its central course. As the lateral flow of the swelling water comes in con. tact with the shore it is checked and reflected back, causing a series of small undulations or wavelets, which break at the margin of the water.

Although these waves are small, varying in height, according to the condition of the tide and the slope of the beach, from 6 to 24 inches, they are constant, and never cease during the time that the beach is covered by the tide, the number of them vary. ing from ten to twenty a minute. Allowing a mean of fifteen, this gives a total of 3600 impulses during the period that each tide is acting on the shore. These wavelets are never absent from the shore, except when absorbed by larger waves due to wind. As the wavelets break, the water attains a horizontal movement, and aided by the flood current lifts up and carries forward coarse sand and pebbles in a movement oblique to the coast line, and so gives them a slow but continuous forward movement.

The constant murmur that is heard on a shingle beach on days when there is a total absence of wind, and when the sea is perfectly smooth and calm in the offing, attests the fact that the pebbles on the face of a shingle beach are in constant movement. These tidal wavelets are capable of moving and pushing up the face of a shingle bank pebbles weighing from I or 2 ounces up to 5 or $6 \mathrm{lbs}$. A calculation as to the mechanical power of the water contained in an average sized wavelet shows that the kinetic energy developed amounts to 165 foot lbs., which is capable of lifting 9900 pebbles, each weighing 4 ounces, to a height of I foot. 